\title{
Transcriptome analysis of Haloquadratum walsbyi: vanity is but the surface
}

\author{
Henk Bolhuis ${ }^{1^{*}} \mathbb{D}$, Ana Belén Martín-Cuadrado², Riccardo Rosselli ${ }^{2}$, Lejla Pašić ${ }^{3}$ and Francisco Rodriguez-Valera ${ }^{2}$
}

\begin{abstract}
Background: Haloquadratum walsbyi dominates saturated thalassic lakes worldwide where they can constitute up to $80-90 \%$ of the total prokaryotic community. Despite the abundance of the enigmatic square-flattened cells, only 7 isolates are currently known with 2 genomes fully sequenced and annotated due to difficulties to grow them under laboratory conditions. We have performed a transcriptomic analysis of one of these isolates, the Spanish strain HBSQ001 in order to investigate gene transcription under light and dark conditions.

Results: Despite a potential advantage for light as additional source of energy, no significant differences were found between light and dark expressed genes. Constitutive high gene expression was observed in genes encoding surface glycoproteins, light mediated proton pumping by bacteriorhodopsin, several nutrient uptake systems, buoyancy and storage of excess carbon. Two low expressed regions of the genome were characterized by a lower codon adaptation index, low GC content and high incidence of hypothetical genes.

Conclusions: Under the extant cultivation conditions, the square hyperhalophile devoted most of its transcriptome towards processes maintaining cell integrity and exploiting solar energy. Surface glycoproteins are essential for maintaining the large surface to volume ratio that facilitates light and organic nutrient harvesting whereas constitutive expression of bacteriorhodopsin warrants an immediate source of energy when light becomes available.
\end{abstract}

Keywords: Haloquadratum, Halophile, Transcriptome, Glycoprotein, Bacteriorhodopsin, Archaea

\section{Background}

The halophilic archaeon Haloquadratum walsbyi dominates sodium chloride $(\mathrm{NaCl})$ saturated thalassic lakes worldwide (up to $10^{8}$ cells/ml) $[1,2]$ and may be amongst the more abundant organisms in nature. This microbe is unique due to its peculiar flattened and square shape. After its initial discovery by Anthony E. Walsby in 1980 [3], the organism could not be cultivated for almost 25 years, until 2004 when two strains were isolated and described and their genomes were sequenced. In addition to the Spanish isolate HBSQ001 $[4,5]$ and the $H$. walsbyi type strain, the Australian strain C23 [6, 7], a further 5 strains were isolated (M. Dyall-Smith, personal communication) and two partial genomes were assembled from metagenome datasets [8]. H. walsbyi HBSQ001, is a true halophile that under laboratory conditions grows optimally at a doubling time of about

\footnotetext{
* Correspondence: henk.bolhuis@nioz.nl

${ }^{1}$ Department of Marine Microbiology and Biogeochemistry, Royal Netherlands Institute for Sea Research (NOIZ) and Utrecht University, Den Hoorn, the Netherlands

Full list of author information is available at the end of the article
}

10 days in near saturated $\mathrm{NaCl}$ media $(3.3 \mathrm{M})$ with high concentrations of $\mathrm{MgCl}_{2}(2 \mathrm{M})[4,6]$. In natural brines, $H$. walsbyi succeeds as a $K$-strategist, species with overall lower energy demands that are capable of efficiently utilizing a vast number of scarce resources $[9,10]$, in contrast to $R$ strategists, that are mainly fast-growing organisms adapted for high resource utilization. The essential resources for $H$. walsbyi are mainly provided by the main primary producer in hypersaline ecosystems, the halophilic microalgae Dunaliella salina [11].

The genome sequence of $H$. walsbyi HBSQ001 yielded several interesting and unique features that were not found in other haloarchaea or any other archaea in general [5]. Unique for haloarchaea is its relatively low GC content (47.9\%), with values between $60 \%$ and $65 \%$ for most other haloarchaea [12]. Amongst others, the genome encoded several extracellular glycoproteins including the extremely large halomucin, an exo-glycoprotein of 9159 amino acids that is probably involved in protecting the cell against dehydration and phage attack [13], and several proteins involved in phosphate and phosphonate metabolism. Unique 
amongst prokaryotes in general is the extreme low protein coding gene density (76.5\%), a value that normally lies between $85 \%-90 \%$ in prokaryotes [14]. H. walsbyi is capable of phototrophic growth which is facilitated by a conserved haloarchaeal type bacteriorhodopsin (BopI) that functions as a light driven proton pump [15], generating a transmembrane proton gradient that can be used to drive ATP synthesis via the membrane ATP synthase and to drive other transport processes [16]. A second bacteriorhodopsin coding homolog, bopII, is a phylogenetic deep-rooting gene, meaning that it is evolutionary closely related to the common ancestor of currently known bop genes although its function is yet to be determined. The genome sequence also revealed genes encoding the two dominant types of intracellular structures: gas vesicles that allow buoyancy and polyhydroxybutyrate granules that store energy.

What the genome sequence could not explain is one of the most fascinating features of $H$. walsbyi, its square morphology and extreme flatness (about 0.1$0.2 \mu \mathrm{m})[3,17,18]$. It was hypothesized that the cells aim to maintain an optimal surface to volume ratio to facilitate the membrane related processes for nutrient uptake and phototrophy [4, 19] which is achieved by an extreme flatness. As a consequence, cell division in these large sheets results in square corners, while maintaining the high surface to volume ratio may be one of the distinctive features that makes $H$. walsbyi the most abundant species in hypersaline ecosystems [19].

To date, only a few halophilic Archaea have been subject to sequence based transcriptome analysis. Initially, micro-array studies were performed to study gene expression in Halobacterium sp. NRC-1 revealing high responsiveness to its environment, especially to changes in salt conditions [20]. A micro-array based comparison between three haloarchaea, Halorubrum lacusprofundi, Haloferax volcanii and Halobacterium sp. NRC-1 examined growth at increased acidity or alkalinity, and revealed a response in regulating stress, motility, and $A B C$ transporter expression as is seen in prokaryotes in general [21]. H. volcanii and Halobacterium sp. NRC-1 were studied with a strong focus on the analysis of noncoding small RNA (nc-sRNA) [22] which confirmed that haloarchaeal RNA-based regulation plays an important role in gene transcription. Recently, a transcriptome analysis of the halophilic archaeon Halolamina sp. YKT1, isolated from a salt mine in Turkey, was published [23]. The authors compared gene expression under high and low salt conditions and revealed a large number of genes that were either up or down regulated in order to focus its energy towards maintaining the intracellular osmotic balance while minimizing the production of nucleic acids and peptides. High-throughput RNA sequencing was also performed on two closely related strains from the hyper-halophilic bacterium Salinibacter ruber that were grown either separately or in co-culture [24]. Transcriptomic patterns from pure cultures were very similar for both strains with the exception of some genes involved in environmental sensing. In co-culture, a small but significant change in their individual transcription patterns was found as compared to those in pure culture showing that both strains reacted in a strain-specific fashion to the presence of the other at the transcriptional level [24].

To better understand the physiology of $H$. walsbyi HBSQ001 and the possible role of its photoheterotrophic growth, we conducted a transcriptome analysis comparing the transcripts of cells harvested from batch cultures at the end of the exponential phase in the light and $12 \mathrm{~h}$ later in the dark. Here, we show that light or dark conditions do not significantly affect the expression patterns and that most of the highly expressed genes are related to the expression of exo-glycoproteins, light energy conversion, gas vesicle production and polyhydroxybutyrate (PHB) synthesis.

\section{Results \\ General statistics}

RNA sequencing of end exponential phase, dark and light extracted $H$. walsbyi samples (Additional file 1: Figure S1) yielded 111,441,003 and 115,537,266 paired reads, respectively, (Table 1) with an average GC content of $55 \%$. The majority of these reads mapped to the two ribosomal RNA operons $(79.3 \%$ and $78.2 \%$ for the dark and light samples). The dark and light transcriptome contained respectively $2.9 \%$ and $3.4 \%$ reads that mapped to coding sequences (CDS); while $16.5 \%$ and $17.2 \%$ of the reads mapped to intergenic regions. Nearly $1 \%$ and $0.3 \%$ of the sequence reads mapped to two other noncoding RNA features; RNAseP and SRP-RNA (signal recognition particle $7 \mathrm{~S}$ RNA). Most of the tRNA's and other small genetic features $(<150 \mathrm{bp})$ could not be mapped due to the larger inserts ( $>200 \mathrm{bp}$ ) of cDNA fragments required for PE100 sequencing. The average number of transcripts per million (TPM) [25] for the coding region (excluding rRNA and other non-coding RNA features) was 21.3 TPM in the dark and 23.4 TPM in the light (Table 1).

\section{Gene expression comparison between light and dark}

Comparison of the light and dark sample revealed no significant differences (i.e. no expression differences $>2.5$ standard deviation) between the two datasets for both coding sequences and intergenic regions (Fig. 1a and b). Due to the lack of differential gene expression between the light and dark samples we choose to average the expression data obtained from both samples for further analysis. Plotting expression levels per CDS or intergenic region along the genome revealed a clearly uneven distribution of high and low expressed genes (Fig. 2a and b). 
Table 1 H. walsbyi HBSQ001 general RNA sequencing statistics

\begin{tabular}{|c|c|c|}
\hline & \multicolumn{2}{|c|}{ Growth Conditions } \\
\hline & Dark & Light \\
\hline Chromosome length (nt) & $3,132,794$ & \\
\hline $\begin{array}{l}\text { Total number of PE100 reads mapped to } \\
\text { chromosome }\end{array}$ & $111,441,003$ & $115,537,266$ \\
\hline Reads mapped to ribosomal operons & $88,414,038$ & $90,353,332$ \\
\hline Reads mapped to CDS & $3,272,328$ & $3,925,912$ \\
\hline Percent reads mapped to CDS & $2.9 \%$ & $3.4 \%$ \\
\hline Percent reads mapped to ribosomal operons & $79.3 \%$ & $78.2 \%$ \\
\hline Percent reads mapped to Intergenic regions & $16.5 \%$ & $17.2 \%$ \\
\hline Percent reads mapped to UTR's & $15.1 \%$ & $15.2 \%$ \\
\hline $\begin{array}{l}\text { Percent reads mapped to non UTR intergenic } \\
\text { region }\end{array}$ & $1.5 \%$ & $2.0 \%$ \\
\hline Percent reads mapped to SRP RNA & $0.31 \%$ & $0.28 \%$ \\
\hline Percent reads mapped to RNAseP & $0.88 \%$ & $0.95 \%$ \\
\hline Average coverage per nucleotide & $199 x$ & $245 \times$ \\
\hline Median number of reads per CDS & 370 & 430 \\
\hline Average number of reads per CDS & 1155 & 1386 \\
\hline Median TPM per CDS & 8.8 & 9.9 \\
\hline Average TPM per CDS & 21.3 & 23.4 \\
\hline $\begin{array}{l}\text { Percentage of CDS expressed (>Percentile } 10 \\
\text { (less than } 37 \text { and } 43 \text { reads) }\end{array}$ & $17.6 \%$ & $17.2 \%$ \\
\hline Percentage of CDS expressed (>0 reads) (6 CDS) & $94.6 \%$ & $94.9 \%$ \\
\hline GC & $55 \%$ & $54 \%$ \\
\hline
\end{tabular}

CDS, coding DNA sequence; IR, intergenic region

When comparing the first with the second half of the genome, the average transcription rates (in TPM) were similar (54 vs $46 \%$ ). However, when we divided the genome in 4 equal parts, the distribution of highly expressed genes in respective quarters was Q1 - 53\%, Q2 - 1\%, Q3 - 44\% and Q4 - 2\%, revealing two highly expressed genomic regions and two poorly expressed regions. Since this distribution could be caused solely by the 30 highest expressed genes (>200 TPM) we removed these from the calculation but still showing that overall expression levels in the first and third quarter were higher than in the other two quarters, although the differences were much less obvious $(\mathrm{Q} 1$ 36\%, Q2 - 15\%, Q3 - 25\% and Q4 - 24\%, respectively).

\section{Abundantly and lowly expressed genes}

Thirty non-clustered protein coding genes were expressed at more than 10 times the average (Table 2). The three most highly expressed genes were the $\operatorname{csg}$ gene (HQ1207A) at 1843 TPM, encoding a 988 amino acid long S-layer glycoprotein gene (Fig. 3a), directly followed by bopI (HQ1014A) at $1833 \mathrm{TPM}$, encoding the proton pumping bacteriorhodopsin (Fig. 3b), and HQ1205A at 1050 TPM, a gene encoding a 1627 amino acids long cell surface glycoprotein that is probably a component of the cell wall

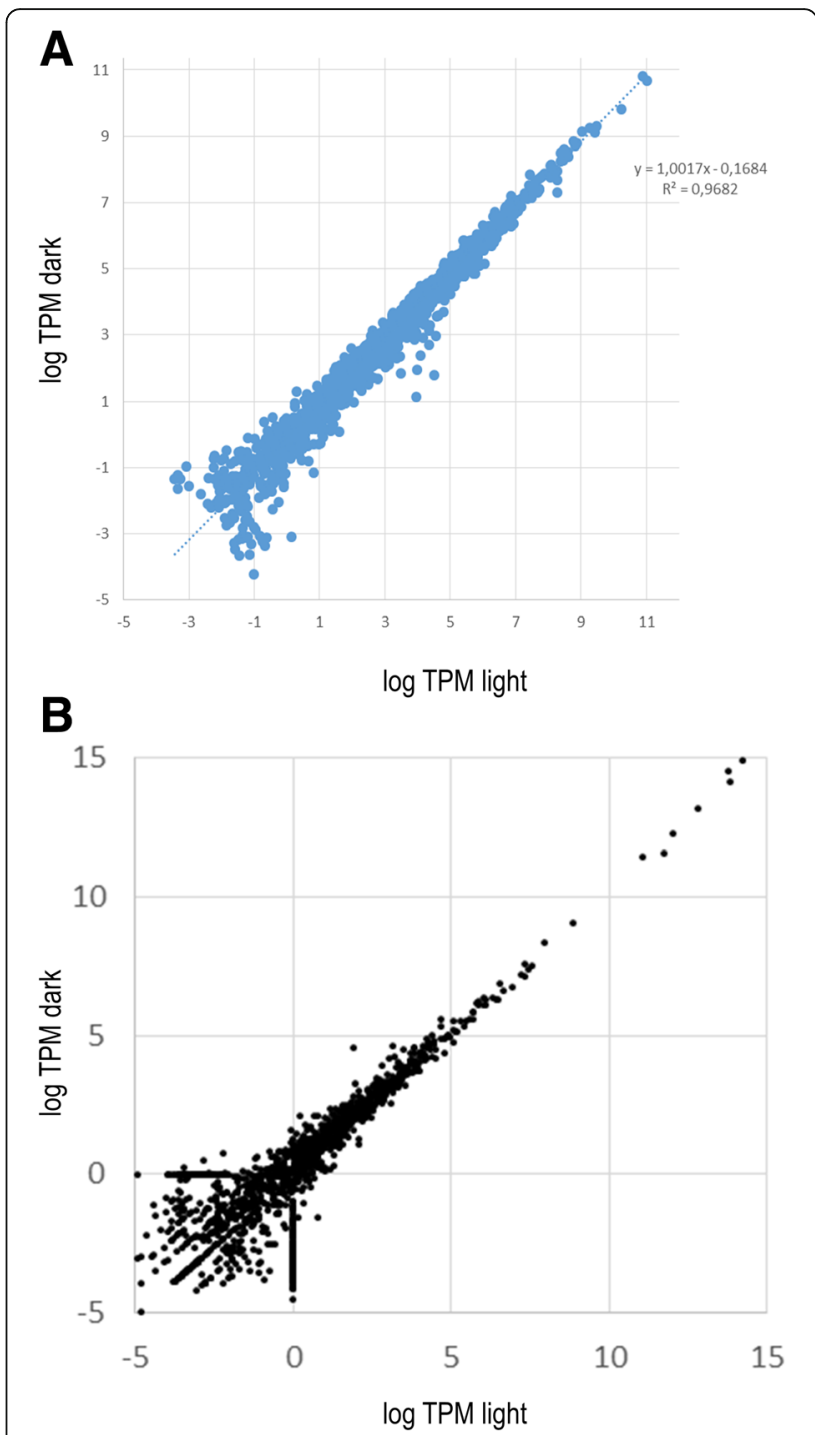

Fig. 1 Comparison of gene expression between the light and dark sample for the protein coding sequences (a) and intergenic regions (b). The expression levels in TPM were log transformed

together with csg [26] (Fig. 3a). Other highly expressed genes encoded proteins involved in oxygen radical stress response (superoxide dismutase; HQ2461A and peroxiredoxin bcp4; HQ3020A) or cell division (ftsZ2; HQ1415A, ftsZ1; HQ1243A and sepF; HQ3071A).

The second bacterioopsin gene, bopII had an expression level slightly above average but much lower than bopI under the conditions studied (Fig. 3b). In contrast, the expression of genes bat (bacterioopsin activator) and bap (bacterioopsin accessory protein), both considered to be essential for rhodopsin function [27], was almost two times higher than average (Additional file 2: Figure S2). As expected, amongst the 214 genes that are expressed at more than 5 times average, 21 encode for ribosomal proteins and 


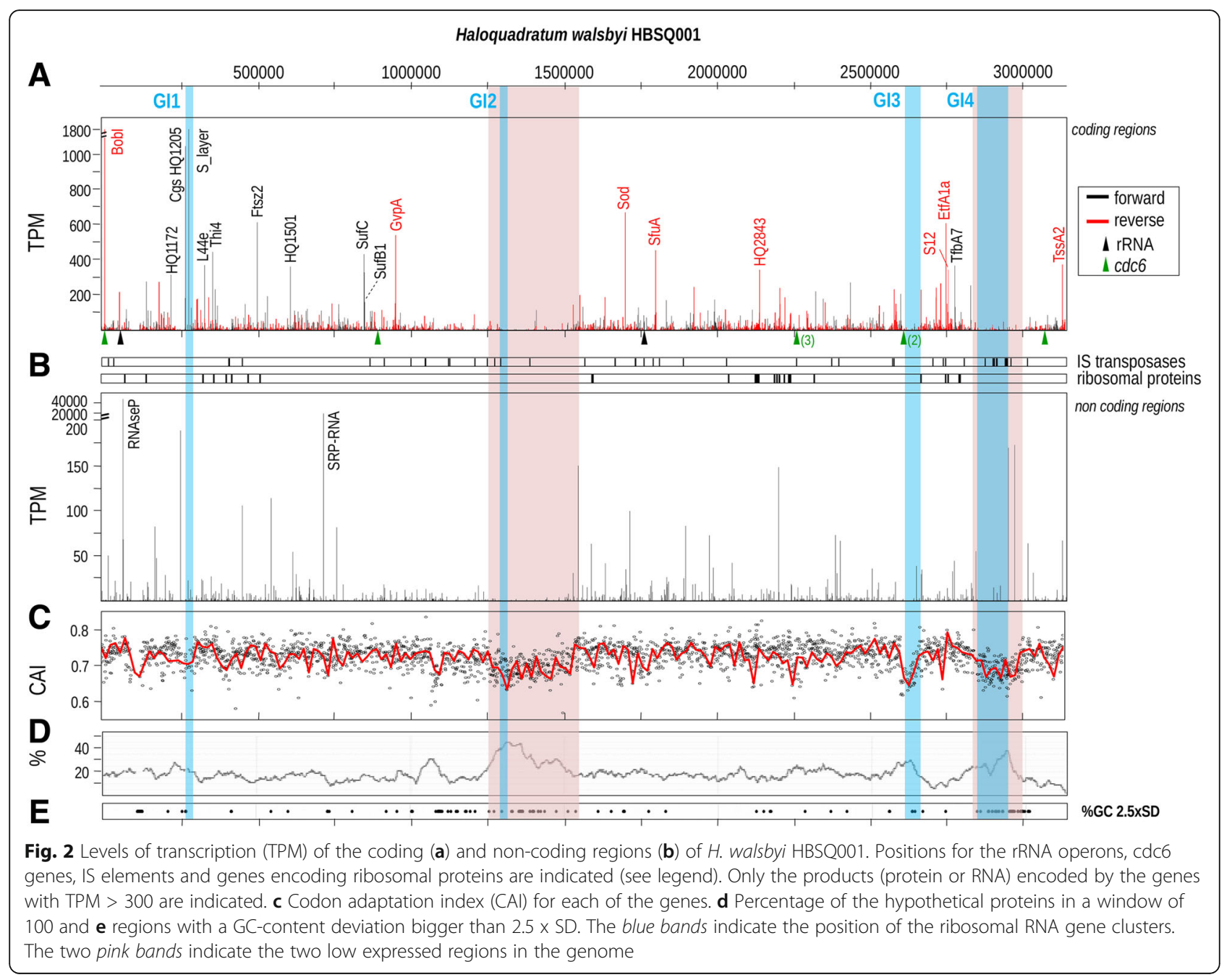

16 encode for proteins involved in transcription and translation initiation and regulation (Additional file 3: Table S1 Sheet 1).

A number of highly expressed genes were found to be part of larger gene clusters. Nearly all genes in the V-type ATP synthase coding cluster (atpDBAFCEKIH) were highly expressed (Fig. 3C). The most highly expressed gene within this cluster was atpD which, together with poorly expressed $a t p F$ encodes the central rotor axle of the ATPase [28]. The gas vesicle producing gvp cluster was also highly expressed, especially the major structural protein coding gene $g \nu p A$ ( $\sim 25$ times average) and, to a lesser extent, $g v p C$ ( $\sim 5$ times average) (Fig. 3D). The other genes in this cluster were expressed below ( $g \nu p M L K J G)$ or slightly above ( $v v p I H F O N)$ average. Within the cluster involved in PHB synthesis, two hypothetical protein coding genes (HQ2312A and HQ2313A) were expressed 5 to 10fold higher than average, whereas phaB encoding the NADPH-dependent acetoacetyl-CoA reductase and phaC encoding the PHB synthase were expressed at an average level (Additional file 3: Table S1 Sheet 2). The gene moaC, which encodes an enoyl-CoA hydratase involved in supplying (R)-3-hydroxyacyl-CoA from the beta-oxidation pathway to the PHB biosynthetic pathway, was also highly expressed (7-fold average). Another cluster, whose genes showed above average expression was nuo cluster that encodes the proton-translocating NADH dehydrogenase. In particular higher expression was observed with genes $n u о A, n u о B$ and $n u о C D$ that encode the structural subunits of the dehydrogenase complex (Additional file 3: Table S1 Sheet 2). Of the 58 ribosomal proteins identified in the transcriptome, 22 were expressed more than 2 times average and 9 were expressed more than 5 time average (Additional file 3: Table S1 Sheet 3). The genes encoding the TCA cycle proteins are located at different regions of the genome but are all expressed above average (Additional file 3: Table S1 Sheet 4).

The transcriptome contained transcripts of 221 transport protein coding genes, 34 of which were expressed above average, with the relative expression of 17 genes exceeding the average at least 2 times (Additional file 3: Table S1 Sheet 5). Fifteen of these genes encoded ABC- 
Table 2 Highest expressed genes with expression levels (TPM) more than 10 times the average per coding sequence, sorted in order of expression level

\begin{tabular}{|c|c|c|c|}
\hline Gene-designation & gene & TPM & Function \\
\hline HQ1207A & $\operatorname{csg}$ & 1843 & Cell surface glycoprotein \\
\hline HQ1014A & bopl & 1833 & Energy conversion \\
\hline HQ1205A & HQ1205A & 1050 & Cell surface glycoprotein/ adhesin \\
\hline HQ2461A & sod & 671 & Superoxide dismutase \\
\hline HQ1415A & $\mathrm{ftsZ2}$ & 615 & Cell division protein \\
\hline HQ3385A & tefla & 610 & Elongation factor 1-alpha \\
\hline HQ1782A & gvpA & 542 & Gas vesicle production \\
\hline HQ2545A & sfuA & 456 & Iron transport \\
\hline HQ1276A & thi4 & 447 & $\begin{array}{l}\text { Putative thiamine biosynthetic } \\
\text { enzyme }\end{array}$ \\
\hline HQ1706A & sufC & 432 & Fe-S cluster assembly ATPase \\
\hline HQ3729A & $\operatorname{tss} A 2$ & 374 & Sulfurtransferase \\
\hline HQ1253A & rp/42e & 370 & $50 S$ ribosomal protein $L 44 \mathrm{e}$ \\
\hline HQ3408A & $t f b A 7$ & 369 & Transcription initiation factor IIB \\
\hline HQ1501A & HQ1501A & 363 & Uncharacterized protein \\
\hline HQ3391A & $\operatorname{rps} 12$ & 346 & $30 \mathrm{~S}$ ribosomal protein S12 \\
\hline HQ2843A & HQ2843A & 346 & $\begin{array}{l}\text { Uncharacterized protein -DUF171 } \\
\text { family }\end{array}$ \\
\hline HQ1707A & sufB1 & 331 & Fe-S cluster assembly \\
\hline HQ1172A & HQ1172A & 318 & $\begin{array}{l}\text { RNA binding / TRAM domain } \\
\text { protein }\end{array}$ \\
\hline HQ1100A & HQ1100A & 279 & Uncharacterized protein \\
\hline HQ1133A & HQ1133A & 276 & Uncharacterized protein \\
\hline HQ3117A & $c i t B$ & 274 & $\begin{array}{l}\text { Aconitate hydratase (TCA cycle } \\
\text { enzyme) }\end{array}$ \\
\hline HQ3366A & HQ3366A & 269 & Uncharacterized protein \\
\hline HQ3457A & fer 7 & 258 & $\begin{array}{l}\text { Ferredoxin (2Fe-2S) - electron } \\
\text { transfer }\end{array}$ \\
\hline HQ2649A & HQ2649A & 247 & $\begin{array}{l}\text { Uncharacterized protein -DUF293 } \\
\text { domain }\end{array}$ \\
\hline HQ3356A & porA & 243 & $\begin{array}{l}\text { pyruvate: ferredoxin } \\
\text { oxidoreductase }\end{array}$ \\
\hline HQ2902A & rp/10 & 243 & 50 S ribosomal protein L10 \\
\hline HQ1283A & rp/43e & 235 & $50 S$ ribosomal protein $\mathrm{L} 43$ \\
\hline HQ3242A & $a t p D$ & 234 & V-type ATP synthase subunit D \\
\hline HQ3309A & rps8e & 232 & $30 \mathrm{~S}$ ribosomal protein S8e \\
\hline HQ3020A & bсp4 & 223 & Peroxiredoxin \\
\hline
\end{tabular}

type transporters that depend on ATP as driving force. The other two genes encoded a putative drug/metabolite transporter (DMT superfamily) and a substrate binding protein of a TRAP transporter gene cluster (HQ1442AHQ1444A) whose substrate is currently unknown. In total, 7 of these 17 transport related genes encoded substrate binding proteins. The highest expressed gene cluster amongst these encodes an iron transport protein complex
SfuABC of which the substrate binding protein coding gene, sfuA (HQ2545A), is amongst the highest expressed genes overall (Table 2). Genes encoding another putative ABC-type transport system is also involved in iron scavenging and Fe-S cluster assembly [29] (sufAB1B2; HQ1706A-HQ1708A). Two other highly expressed genes encoding transporters are involved glutamine./glutamate $(g \ln H-\mathrm{Hq} 2732 \mathrm{~A})$ and in copper uptake (nos $Y$ HQ1143A). Finally, H. walsbyi HBSQ001 contains 7 gene clusters encoding $\mathrm{ABC}$-type branched-chain amino acid transport systems, each consisting of 5 genes (livFGHJM17). In 5 of these liv clusters only the substrate binding protein coding gene livJ is expressed above average.

In the cultures, that were supplemented with glycerol and sodium pyruvate as carbon and energy source, a higher than average expression was found for several genes involved in glycerol metabolism (Additional file 3: Table S1 Sheet 6). The glycerol kinase gene ( $g l p K: \mathrm{HQ} 1733 \mathrm{~A})$ was nearly 5fold higher expressed than average. Its neighboring gene HQ1732A that expressed a putative protein with unknown function is polycistronic transcribed at a more than 2.5 fold higher level than average. More than 2 fold higher expression than average was also found for the alpha subunit of glycerol-3-phosphate dehydrogenase encoded by the $g l p A$ gene that belongs to the $g \operatorname{lp} A B C$ gene cluster and is located directly downstream of $g l p K$. A second $g l p A$ gene located directly downstream of the cluster dhaKLM (which encodes a low expressed phosphotransferase (PTS) dependent dihydroxyacetone uptake system) was also expressed above average. Methylglyoxal synthase encoded by $m g s A$ (HQ1527A) that converts dihydroxyacetone phosphate to methylglyoxal and phosphate was also highly expressed (107 TPM).

Notably, a significant number of genes encoding hypothetical proteins or proteins with yet unknown function were above average to highly expressed. These include $17 \%$ of the hypothetical protein coding genes expressed at more than 10 fold average and $20 \%$ of these genes expressed at more than 5 fold average.

Nearly 5\% (127) of the annotated genes were not expressed at all and 15\% (417) had on average less than one transcript per million of which $95 \%$ were annotated as hypothetical proteins (Additional file 3: Table S1 Sheet 7). The only unexpressed gene with clear annotation encodes for an L-lactate permease (HQ2551A). The highest density of low- to non-expressed genes was found at the end of the first (from position 1.250.000 to 1.530.000) and second half of the genome (from position 2.850 .000 to 3.030 .000 ) (Fig. 2). These low expressed regions are characterized by an on average lower codon adaptation index (CAI) (Fig. 2c), higher GC content (Fig. 2d) and were rich in hypothetical genes for which it is yet unclear whether they are translated to proteins under any condition (Fig. 2c and d). Of the previously identified genomic islands (GI's), two 

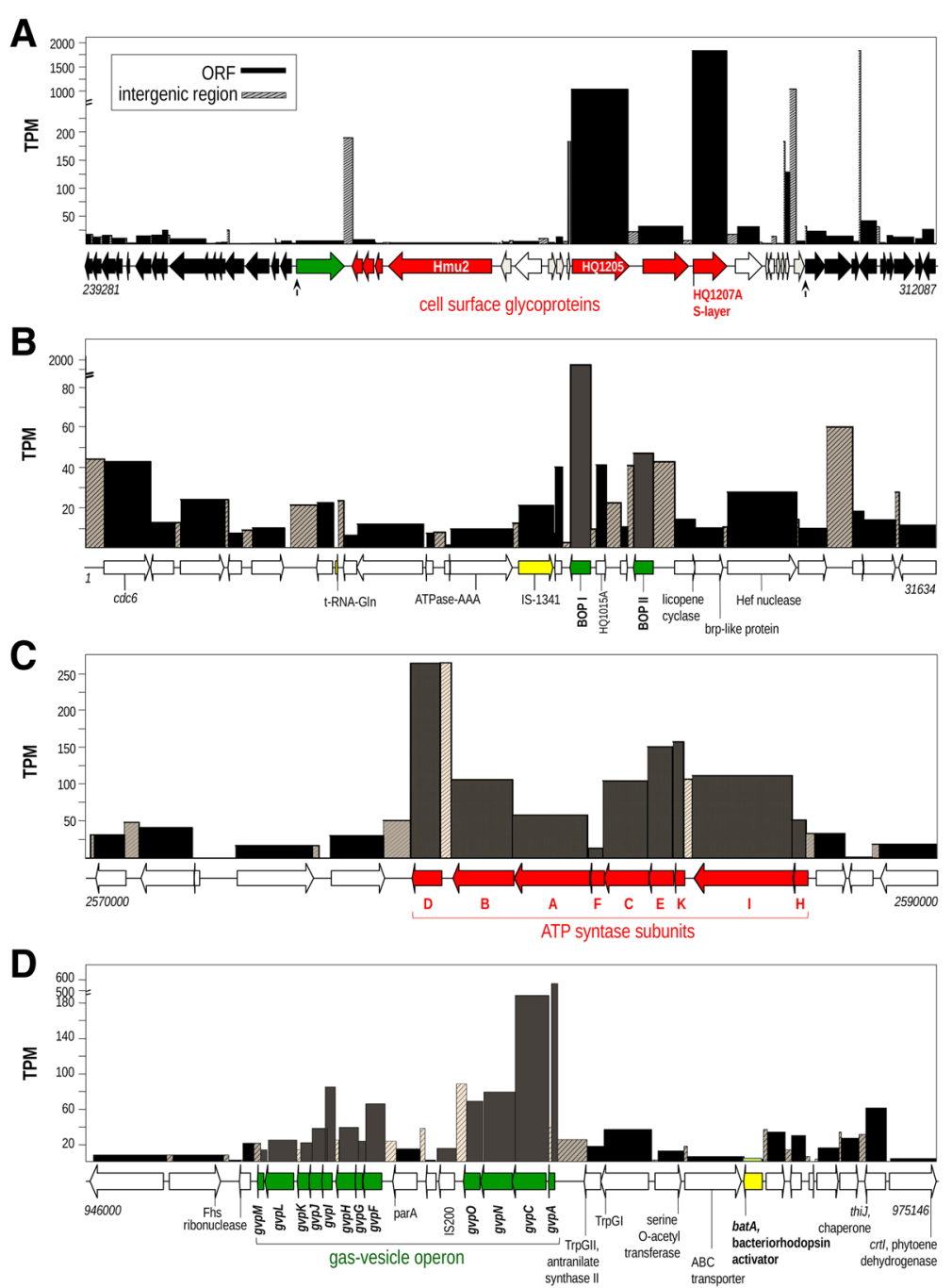

Fig. 3 Expression of regions of interest. (a) Genomic island 1, Arrows indicated the beginning and the end of Gl1 accordingly to Martin-Cuadrado et al. 2015 [26]. (b) Bacterioopsin genes bopl and bopll. (c) ATP synthase gene cluster and (d) the gas vesicle synthesis operon

including the largest (GI4) overlap with the low expressed regions (Fig. 2). Amongst the very low expressed genes were hmu (3.3 TPM) (Additional file 2: Figure S2), the gene that encodes the giant halomucin protein (9159 amino acids) as well as the two smaller halomucin genes hmu2 (2.7 TPM) and hmu3 (5.1 TPM). We also analyzed the genes encoded on the plasmid PL47, however only two of the plasmid encoded genes, HQ4010A and HQ4030A were significantly expressed and both encode hypothetical proteins with unknown function.

\section{Expression patterns in functional groups}

Expressed genes were classified in functional groups according to the arCOG database [30] (Additional file 3: Table S1 Sheet 8). The distribution of median expression levels within these groups is presented as a boxplot of the $\log$ transformed expression values comprising all protein coding genes present in the genome including those that are not expressed (Fig. 4a). Median expression is highest in genes involved in energy production and conversion (arCOG group C) followed by intracellular trafficking, secretion, and vesicular transport (arCOG group U) - translation, ribosomal structure and biogenesis (arCOG group J) - posttranslational modification, protein turnover, chaperones (arCOG group $\mathrm{O}$ ) and cell cycle control, cell division or chromosome partitioning (arCOG group D). When only considering the top 200 highly expressed genes with expression levels larger than 2.5 times the average and more than 2 representatives per functional group, the highest median values are found for genes encoding proteins related to cell wall/membrane/envelope biogenesis (arCOG group $\mathrm{M})$, secondary metabolites biosynthesis, transport and catabolism (arCOG group Q), coenzyme transport and metabolism (arCOG group $\mathrm{H}$ ), general function prediction 

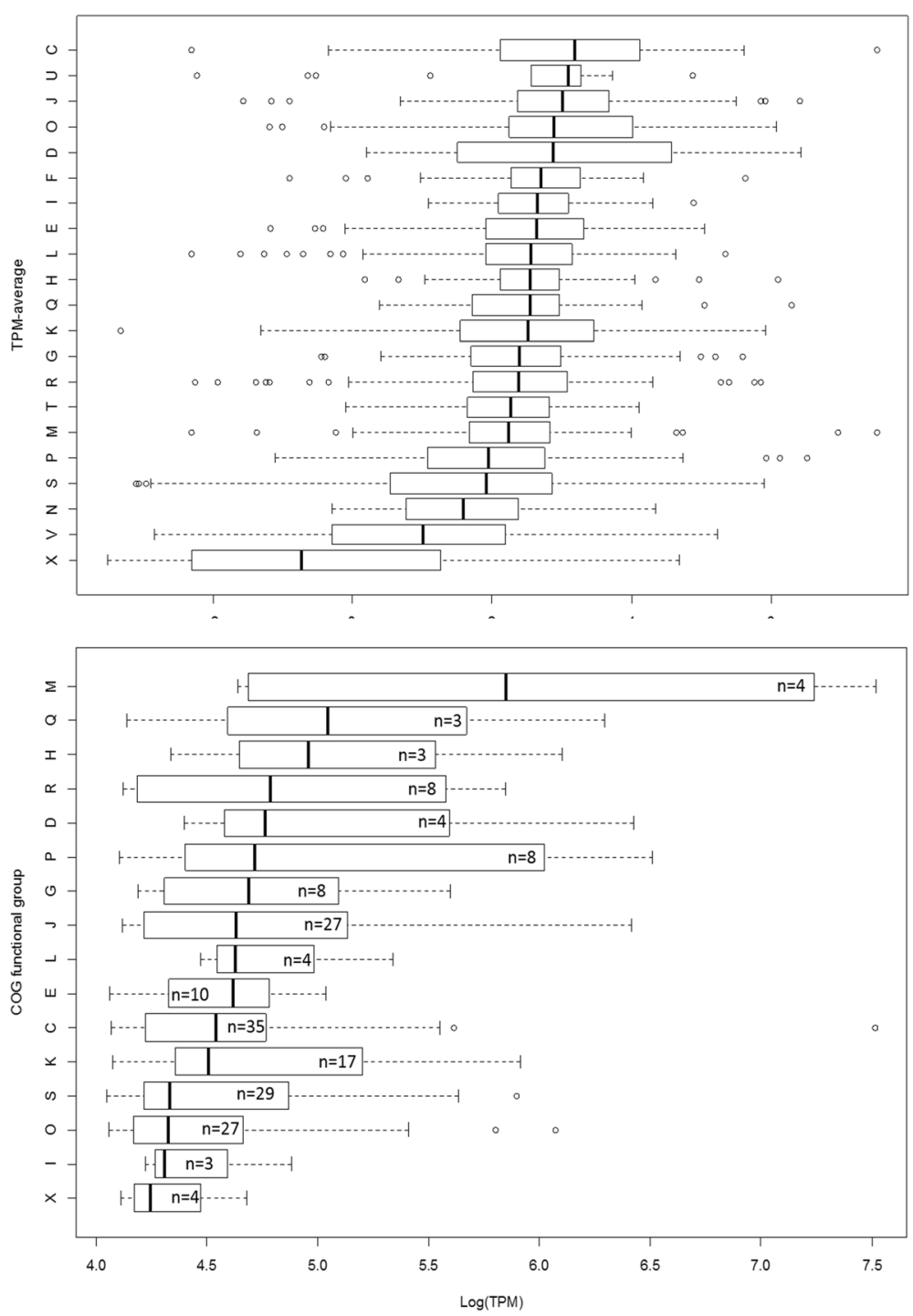

Fig. 4 Median gene expression ranked by COG functional groups of the total protein coding dataset (a) and of the top 200 highest expressed genes (b)

(arCOG group R) and cell cycle control, cell division, chromosome partitioning (Fig. 4B). Overall the median expression level for energy related processes in the top 200 is low with the exception of one outlier, the above mentioned gene bopI.

\section{Small RNA's and other genome features}

Putative small non coding RNA's (snRNA), some of which were previously unannotated in the genome, could be identified in the transcriptome data. After excluding ribosomal RNA genes and putative snRNA genes that overlapped with previously annotated coding regions, 147 putative snRNA genes could be detected within the $H$. walsbyi chromosome plus 6 on the plasmid PL47. The identified snRNA genes were clustered into four categories crRNA, ncrNA, snoRNAs and tRNA genes. CRISPR (clustered regularly interspaced short palindromic repeats) RNAs (crRNA) are RNA molecules that provide protection against phage and plasmid infection. H. walsbyi HBSQ001 contains one CRISPR region composed of five spacers flanked by seven direct repeats of 25 bp while putative Cas proteins were not identified in this strain. In addition, the CRISPR region is interrupted by a putative insertion sequence element. Nevertheless, the CRISPR region is significantly expressed. $H$. walsbyi HBSQ001 expresses 79 non-coding RNA (ncRNA) that range in size from 30 to $495 \mathrm{bp}$. The levels of expression of two of these ncRNAs are surpassed only by the ribosomal rRNA genes. These are the 7SL RNA, which has a signal recognition function to guide membrane proteins to the protein translocation complex and the ribozyme RNase P. Other high expressed ncRNAs 
were SECIS (selenocysteine insertion sequence), involved in the translation of UGA codons as selenocysteines and $\mathrm{HgcC}$ ("high GC" family RNA) with unknown function. Small nucleolar RNAs (snoRNA) are well-characterized small RNAs that play a role in the nucleus of eukaryotes but are also found in archaea. Two classes of snoRNAs have been characterized that are involved in the modification of rRNA, C/D-box RNAs, which guide methylation sites in rRNAs, and H/ACAs RNAs involved in pseudouridine formation. In $H$. walsbyi HBSQ001, 24 C/ D-box RNAs are found in the major chromosome and 6 on the plasmid and had variable expression levels. H/ ACAs RNAs were not identified. Most tRNAs were lost in the sequencing processing with the exception of the tRNA-Trp, the largest tRNA with 178 bp compared to the approximate 75 bp of other tRNAs. Putative circular cRNA molecules were not detected.

\section{Discussion}

\section{No differential gene expression between light and dark} period

Although Archaea are generally not known for having an endogenous molecular clock that may regulate gene expression in a circadian rhythm, $H$. walsbyi is a photoheterotrophic organism that may benefit from differential gene expression during the light or dark period in putting less energy towards the synthesis of light dependent proteins such as both bacteriorhodopsins and halorhodopsin, a light driven chloride transporter. Similar mechanisms are well described for Cyanobacteria in which a controlled sequence of phosphorylation and dephosphorylation of the key circadian clock protein (KaiC) is responsible for the regulation of gene transcription of a large number of genes [31]. However, outside the Cyanobacteria no circadian regulation is observed in prokaryotes. When comparing the transcriptome from the light and dark sample, no significant difference (expression differences $>2.5$ standard deviation) in gene expression was observed throughout the genome. We can therefore conclude that gene expression in $H$. walsbyi is not regulated by a circadian like mechanism that switches gene expression patterns within $12 \mathrm{~h}$ nor does it appear to be regulated by light or darkness as physiological cues. However, due to the lack of significant differences the two samples could now be considered as a biological replicate from which we used the mean values to analyze genome wide gene expression patterns. Existence of putative circadian clock like mechanism can however not be ruled out amongst other haloarchaea. Microarray analysis of gene transcripts in Halobacterium NRC-1 grown under a $12 \mathrm{~h}$ light / $12 \mathrm{~h}$ dark regime did reveal significant diurnal oscillatory transcription in up to $12 \%$ of its genes including free-running behavior after the light dark stimulus is stopped [32].

\section{Energetics}

Despite the absence of a light/dark differential regulation, light is an important driver in energy generation given the high expression of bopI, the second highest expressed gene overall. In the light, bacteriorhodopsin is involved in the generation of a proton gradient which in turn can be used to drive a multitude of proton dependent transmembrane transport processes. Why bopI expression is high even in the dark is unknown. Potentially there is a high turnover of this protein although that would not be in accordance with the highly stability and stress resistance characteristics of bacteriorhodopsins in other Halobacteria that in fact are amongst the most stable proteins known to date [33]. High expression of rhodopsins is also found in $\mathrm{H}$. salinarum strain R1 under both light and dark conditions [34] and in the bacterium $S$. ruber that expresses a xanthorhodopsin gene encoding a homologous light dependent proton pump [24]. Also the green light absorbing proteorhodopsin (PR) of the flavobacterium Dokdonia donghaensis PRO95 expressed its PR gene both in the light and in the dark even though light was not found to stimulate growth [35]. Several $H$. walsbyi genes are identified to encode putative regulators of bopI expression; a small zinc finger protein, HQ1083B, and a small basic protein, Bp (HQ1083A). Both cooperate with Bat proteins to activate bopI transcription under phototrophic growth conditions in $H$. salinarum R1. HQ1083A and bat were both expressed above average and therefor explain the high expression of bopI. However, the physiological significance of high bopI expression especially in the dark remains unclear. A second zinc finger protein with unknown function, HQ1015A that is divergently transcribed directly upstream of bopI is also highly expressed. Based on analogy with a homologous protein in $H$. salinarum, HQ1015A is likely also involved in the regulation of bopI transcription [36]. The second bacterioopsin coding gene bopII that is located within three genes from bopI is expressed above average. This phylogenetic deeply rooting protein may not function as a light driven proton pump but instead may have a sensory function, although motility in Haloquadratum is apparently limited to controlling buoyancy via the gas vesicles. The expression of the haloopsin gene is below average but this is apparently sufficient to fulfil its role as light driven chloride pump. Proper function of the opsin proteins is dependent on the retinal chromophore of which a key enzyme, phytoene synthetase, encoding gene $\operatorname{ctr} B(\mathrm{HQ} 2860 \mathrm{~A})$ is expressed at nearly 3 fold average. 
The light generated proton gradient can be efficiently used by several proton translocating protein complexes such as the proton dependent ATPase, generating the universal energy storage molecule ATP, and it can drive the reverse process of the proton translocating NADH dehydrogenase. Genes encoding both complexes are highly expressed underlining the need for ATP and reducing equivalents such as NADH. Like other photoheterotrophic prokaryotes, Haloquadratum could use the surplus in light generated proton gradient via a reverse electron transport mechanisms through the NADH dehydrogenase that reduces NAD+ to NADH in the process. Together these processes allow for optimal and efficient use of the light generated proton gradient.

In the HAS growth medium and in the natural ecosystem, the main organic carbon and energy source is glycerol, not surprisingly a whole suit of transcripts for the enzymes involved in glycerol metabolism, glycerol kinase (GlpK) and glycerol-3P dehydrogenase (GlpA), were highly expressed. This includes HQ1732A the gene encoding an uncharacterized putative membrane protein with 7 predicted transmembrane helices located immediately upstream of $g l p K$. Homologs of the HQ1732A gene product are found in other haloarchaea with between 6 and 8 transmembrane helices and in all instances in the string database (https://string-db.org/) found in close association with glycerol kinase and glycerol-3P dehydrogenase. Potentially this protein and its homologs may play an essential role in glycerol metabolism or even glycerol uptake. Low expression of genes involved in the unique archaeal phosphotransferase uptake system involved in DHA metabolism possible reflects the absence of DHA or a DHA producer like Salinibacter ruber [37] in the medium used.

\section{Patterns in genome wide expression levels}

A significant percentage of the dark (16.5\%) and light (17.2\%) reads mapped to intergenic regions of which approximately $90 \%$ can be attributed to potential untranslated but transcribed regions (UTRs). Expression levels of these UTRs can be several tens of folds higher than the actual coding sequence. Although both 5'and 3' UTRs play a significant role in gene expression [38], we cannot simply translate and compare UTR expression levels and infer actual protein synthesis rates. Therefor we only focused on the expression of the protein coding sequence itself for comparison.

Two highly expressed regions were identified on the genome as well as two poorly expressed regions. The high and low expressed regions are found at the beginning and ends of the two halves of the genome. Commonly prokaryotes have a single origin of replication with most of the housekeeping genes and the ribosomal RNA gene cluster (5S, 16S and 23S rRNA) located near the origin [39]. Moreover, transcription levels are also higher near the origin or replication [40]. H. walsbyi encodes two rRNA gene clusters and high expression levels are centered on both clusters. The reason for the high expression of genes in the region of the second rRNA cluster, far from the origin of replication is unknown. Potentially it reflects an ancient genome duplication event with a remnant or independent second origin of replication, a feature not uncommon in Archaea, given the detection of three origins of replication in Sulfolobus species [41, 42]. However, cdc6-like DNA replication protein coding genes, like the one associated with the established origin of replication in $H$. walsbyi are not found in close proximity of the second 16S rRNA cluster. Moreover, several typical housekeeping genes like those involved in the TCA cycle are not located near the origin but rather in the second half of the genome near the second rRNA gene cluster and three alternative $c d c 6$ like DNA replication protein coding genes (orc4, orc6, orc7). The poorly expressed regions at the end of the first and second half of the genome are characterized by an on average higher GC content and are rich in hypothetical genes with unknown function. Potentially this part of the genome is rich in horizontally acquired genes that may serve as a genetic toolbox for future environmental challenges or is only expressed in the natural environment. The only plasmid (PL47) of strain HBSQ001 serves a potential similar role since only two of the 36 genes were expressed under the imposed cultivation conditions.

\section{Gene expression of a hyperhalophile}

The square extreme halophile $H$. walsbyi is in many ways enigmatic. Not only is it capable of maintaining a unique square morphology, it does so at extreme high salinities far above $\mathrm{NaCl}$ saturation and is widespread in these hypersaline environments [3, 17-19, 43, 44]. Maintaining membrane integrity and protecting cells against desiccation and other stresses in this hostile environment requires specific adaptations at both genetic and physiological level. This transcriptome analysis clearly reveal the importance of maintaining membrane integrity by two highly expresses genes encoding putative extracellular S-layer glycoproteins in the top three, gene HQ1205A and HQ1207A. Surprisingly, the large, 27,477 nucleotide long halomucin coding gene is expressed below average. Low expression is also observed in the other two halomucin coding genes. Potentially only a few mRNA copies are required to produce sufficient halomucin proteins and to reduce energy and resources needed for the synthesis and translocation of these costly proteins [13]. Moreover, it has been argued that halomucin may also be involved in protection against the abundant halophages present in their natural habitat but 
absent in pure cultures of $H$. walsbyi HBSQ001, a defense mechanism also found to protect mammalian epithelial cells [45]. High expression of the cell surface glycoproteins HQ1205A (4881 bp) and HQ1207A (2967 bp) is apparently sufficient to protect membrane integrity at the extant cultivation conditions. The gene in between, HQ1206A, encodes a third, 3780 bp long cell surface glycoprotein and is moderately expressed while HQ1204A, directly upstream of this cluster is highly expressed. However, HQ1204A is a much smaller gene (216 bp) and encodes a putative CopG/RHH family DNA binding protein that might be involved in regulation of the adjacent cell surface glycoprotein genes.

Gas vesicles may play an important role in supporting aerobic growth, especially in solar salterns where oxygen dissolution close to the surface is limited and other means of motility like a flagella are lacking in $H$. walsbyi. Alternatively gas vesicles may play a role in aligning the cells with their surface to the sun for optimal generation of the bacteriorhodopsin derived proton gradient. Indeed, $H$. walsbyi invests lots of energy in the production of gas vesicles which is evident from the abundantly present number of gas vesicles in its cells and the high expression levels of gas vesicle genes. High expression is evident in the two major structural protein coding genes $g v p C$ and $g v p A$, and to a lesser extent $g v p N$ (encoding a chaperone required for the assembly of gas vesicles), $g \nu p O$ (required for gas vesicle synthesis and potential transcription regulator [46]) and gvpI (required for termination of GvpA incorporation in the gas vesicle protein complex [47]). In Halobacterium salinarum growing under anoxic conditions and in the presence of citrate, the gvpACNO genes were found to be significantly overexpressed [48]. Although the gvp gene cluster has a similar arrangement as in H. salinarum and Haloferax mediterranei, two important regulatory genes are absent in $H$. walsbyi. Absence of $g v p E$, a gene encoding a transcriptional activator of GvpA [49] and $g \nu p D$, encoding a protein involved in the repression of the gas vesicle formation [50], suggests a different regulation mechanism for gas vesicles compared to other haloarchaea. Although it was hypothesized that gas vesicle production in $H$. salinarum was stimulated by citrate rather than by anoxic conditions, $H$. walsbyi was grown in the absence of citrate and up-regulation of the $g v p$ genes found in the present study may reflect the sub-oxic conditions in the applied cultivation set up of standing cultures without active aeration by shaking or bubbling with air. However, sub-oxic conditions do not explain the high expression of superoxide dismutase gene ( $(\mathrm{d} d)$. Especially aerobic growth comes with the toll of generating high concentration of oxygen radicals and hence the need for a detoxifying SOD protein [51]. However a basic expression of sod in $H$. cutirubrum was found under anaerobic conditions while expression was induced in the presence of paraquat, a generator of oxygen radicals [52]. What causes the high expression in $H$. walsbyi under the extant growth conditions is unknown but continuous presence of SOD is essential for reducing cumulative oxidative damage [51].

High expression of the substrate binding protein coding gene (livJ) from 5 of the 7 clusters encoding ABC-type branched-chain amino acid transporters may indicate a potential shortage in amino acids or nitrogen in general. Only low concentrations of amino acids are supplied via yeast extract in HAS medium and may explain the need for high expression of substrate binding protein to scavenge the growth medium for branched amino acids (leucine, isoleucine and valine). Having 7 similar gene clusters in the genome may also reflect the high requirement for amino acids in the natural environment. High concentrations of PHB in Bacteria are associated with a carbon overflow mechanism occurring at a relative excess of carbon relative to a limitation of oxygen, nitrogen, phosphorus, or potassium resulting in the accumulation of reducing power [53]. In haloarchaea like $H$. mediterranei, neither oxygen nor nitrogen but rather phosphate limitation is a strong inducer of PHB accumulation [54]. Free phosphate concentrations are naturally low in crystallizer ponds where $H$. walsbyi dominates due to the low solubility of phosphate at the extant high magnesium concentrations. Indeed, $H$. walsbyi is well equipped with a suit of enzymes directed to scavenge phosphates or phosphonate as alternative source of phosphate [5]. Most likely phosphate is present in sufficient quantities since none of the phosphate or phosphonate transporters are significantly over expressed.

In three of the highlighted operons; NADHdehydrogenase, Gas-vesicle biosynthesis and ATPsynthase there are several indications for polycistronic gene transcription which is characterized by short intergenic distances between genes or even overlapping genes and an initial high expression at a single 5'UTR followed by a more or less even read distribution over the genes within the transcription unit [55]. The ATP-syntatse gene cluster appears to consist of three transcription units consisting of the polycistronic clusters atpIH and atpKECFABD and the monocistronic unit consisting of $a t p D$. The units are $>200 \mathrm{nt}$ apart whereas genes within the unit are overlapping $(-3,-13 \mathrm{nt})$ or have a very short, 2-24 nt overlap (Additional file 4: Figure S3A). The NADH-dehydrogenase encoding cluster reveals two putative polycistronic transcription units consisting of nuоABC/DHI and nuоJ1J2KLMN (Additional file 4: Figure S3B). Genes within this cluster either overlap with three nucleotides or are 0,1 or 2 nucleotides apart. In contrast, for the gas vesicle coding $g v p$ gene cluster the situation becomes less apparent. In addition to the 
genes interrupting the gene cluster, the intergenic regions in this gene cluster are overall more spaced (Additional file 4: Figure S3C). Potential polycistronic transcribed units consist of $g v p K J I$ and $g v p H G F$. Although $g \nu p C$ appears to be part of a polycistronic unit based on its 3 nucleotide overlap with $g v p N$, its expression and read coverage is significant higher than for $g \nu p N$, suggesting specific, monocistronic transcriptional control. Together with the highly expressed gene $g v p A$, monosistronic transcription may be essential for the two main structural gas vesicle proteins to achieve the high number of gas vesicles normally observed in the cell cultures.

\section{Conclusions}

Little is known at this moment about gene expression patterns in Archaea in general. The transcriptome analysis of $H$. walsbyi gave insight in a number of highly expressed genes as well as two large regions with very low expression. Gene expression in $H$. walsbyi is all about surface. It devotes a lot of its resources to the expression of genes encoding glycoproteins involved in S-layer biosynthesis and surface protection against desiccation and maintaining the flat square morphology to accommodate a large surface for membrane related processes of energy generation and the uptake of nutrients.

\section{Methods}

\section{Cultivation}

Haloquadratum walsbyi strain HBSQ001 (DSM16790) was cultivated in $1 \mathrm{~L}$ tissue culture flasks equipped with filter screw caps (TPP - Techno Plastic Products AG, Switzerland) containing $300 \mathrm{ml}$ of HAS medium (composition per litre: $195 \mathrm{~g}$ of $\mathrm{NaCl}, 50 \mathrm{~g}$ of $\mathrm{MgSO}_{4} \cdot 7 \mathrm{H}_{2} \mathrm{O}$, $35 \mathrm{~g}$ of $\mathrm{MgCl}_{2} \cdot 6 \mathrm{H}_{2} \mathrm{O}, 5 \mathrm{~g}$ of $\mathrm{KCl}, 0.25 \mathrm{~g}$ of $\mathrm{NaHCO}_{3}, 1 \mathrm{~g}$ of $\mathrm{NaNO}_{3}, 0.5 \mathrm{~g}$ of $\mathrm{CaCl}_{2} .2 \mathrm{H}_{2} \mathrm{O}, 0.05 \mathrm{~g}$ of $\mathrm{KH}_{2} \mathrm{PO}_{4}$, $0.03 \mathrm{~g}$ of $\mathrm{NH}_{4} \mathrm{Cl}, 20 \mathrm{ml}$ of Tris- $\mathrm{HCl}(1 \mathrm{M}, \mathrm{pH} 7.4)$ and as carbon and energy source, $0.5 \mathrm{~g}$ of glycerol and $1 \mathrm{~g}$ of sodium pyruvate [4]). Cells were incubated at $30{ }^{\circ} \mathrm{C}$ under a dark/light regime of $16 \mathrm{~h}$ light and $8 \mathrm{~h}$ dark. Growth was followed spectrophotometrically at $600 \mathrm{~nm}$ (Additional file 1: Figure S1).

\section{RNA extraction}

For RNA extraction, $200 \mathrm{ml}$ samples were taken at the end of the exponential growth phase (Additional file 1: Figure S1). The samples were taken at the middle of the light period and exactly $12 \mathrm{~h}$ later at the middle of the dark period) and kept in the dark in aluminum foil until cell lysis. Per sample, $200 \mathrm{ml}$ of cell culture was centrifuged in 4 aliquots of $50 \mathrm{ml}$ in TubeSpin ${ }^{\circ}$ Bioreactor 50 tubes (TPP) at 5000 G. Supernatant was carefully discarded and remaining medium was removed from the inside of the tube to prevent the high salinity from interfering with the RNA isolation procedure. RNA was extracted from each of the 8 pellets using the ZR Fungal/Bacterial RNA MiniPrep kit (Zymo Research, Irvine, USA) following the manufactures recommendations and eluted in $100 \mu \mathrm{l}$ of elution buffer. After RNA extraction the 4 samples were pooled resulting in one night and one day sample with an average RNA yield of $300 \mathrm{ng} / \mu \mathrm{l}$ and a total yield of $120 \mu \mathrm{g}$. Contaminating DNA fractions were removed using TURBO DNA-free Kit (Ambion, USA) following the manufacturers recommendations. The yield and quality of the resulting RNA fractions were checked on an RNA6000 chip using the 2100 Bioanalyzer system (Agilent, Santa Clara, USA).

\section{Double stranded copy DNA synthesis}

First strand DNA was synthesized using SuperScript III Reverse transcriptase (Invitrogen, Carlsbad, USA) starting with $10 \mu \mathrm{g}$ of RNA. For second strand DNA synthesis we used 30 units of Escherichia coli DNA Polymerase I (New England Biolabs, Ipswich, USA) in the presence of 2.5 units of RNAse $\mathrm{H}$ (Epicentre, Madison, USA), 5 units E. coli DNA Ligase (New England Biolabs, Ipswich, USA), Ligase buffer, DNA Polymerase I Buffer (NEB2) and $300 \mu \mathrm{M}$ of dNTPs. Water was added to $100 \mu \mathrm{l}$ and the mixture was incubated for $150 \mathrm{~min}$ at $16{ }^{\circ} \mathrm{C}$. Subsequently $5 \mathrm{U}$ of T4 DNA Polymerase was added and incubated for a further $30 \mathrm{~min}$ at $16{ }^{\circ} \mathrm{C}$. The final products were cleaned using the cycle pure DNA clean up kit and stored at $-20^{\circ} \mathrm{C}$.

\section{Sequencing}

For high throughput sequencing of the cDNA, both the light and dark samples were sent to BGI (Hong-Kong). High throughput sequencing was performed using the Illumina HiSeq2000 PE100 technology yielding 231 and 222 million reads respectively of $\sim 93 \mathrm{bp}$ length. Mapping statistics can be found in Table 1. Depth of sequencing achieved from Illumina sequencing $(\times 425-500)$ was sufficient to provide adequate coverage of the mRNA fraction without rRNA depletion.

\section{Bioinformatics}

Sequence reads were pre-processed to remove low-quality bases. Reads were first mapped using Bowtie 2 software [56] against HQSB001 ribosomal operon sequences. Remaining reads were subsequently mapped to the chromosome and the plasmid sequence with the default parameters and using the pair-end strategy. SAMtools [57] were used to convert resulting data into BAM format. BamView [58] and Artemis [59] was subsequently used for the visualization of the sequence reads against the $H$. walsbyi HBSQ001 genome. Once the transcripts were mapped to the genome, the expression values of genes were calculated as the number of reads aligned over each coding DNA sequence (CDS). Gene expression values were computed 
using TPM normalization (transcript per million). Genes exhibiting a $>2$ fold log change in TPM between two conditions or strains were considered to have differential expression. To quantify high and low expression values, we used the average median value for all conditions within both strains as a cut-off.

Functional annotation was performed by comparing predicted protein sequences against the NCBI-nr database, Pfam [60] and arCOGS [30] (cut-off E-value $10^{-5}$ ).

CAI was calculated using the program "CUSP" and "CAI" from the EMBOSS package. A subset of 40 ribosomal proteins was used to construct a reference table to which the codon usage of the genes were compared.

The transcriptome sequencing data has been submitted to NCBI SRA and is available with the bioproject number PRJNA362183 and the SRA accession numbers SRR5714110 (light sample) and SRR5714111 (dark sample).

\section{Additional files}

Additional file 1: Growth curve of Haloquadratum walsbyi HBSQ001. (TIFF $1820 \mathrm{~kb}$ )

Additional file 2: Expression of the large halomucin gene, hmu, and the adjacent bat promotor of bacteriorhodopsin production. (TIFF 1506 kb)

Additional file 3: Full list of gene transcription levels ordered by different functional groups. (XLSX $766 \mathrm{~kb}$ )

Additional file 4: Polycistronic and monocistronic transcritpion in A) ATP-synthase gene cluster, B) NADH- dehydrogenase gene cluster and C) gas vesicle gene cluster. (PNG $259 \mathrm{~kb}$ )

\section{Abbreviations}

arCOG: archaeal cluster of orthologous groups; ATP: adenosine triphosphate; bp: base pair; CAl: codon adaptation index (CAl); cDNA: copy DNA; CDS: coding DNA sequence; CRISPR: clustered regularly interspaced short palindromic repeats; DHA: dihydroxyacetone; DNA: deoxyribonucleic acid; Fe-S: iron sulfide; Gl: genomic island; HAS: hypersaline artificial seawater; M: Molar; MgCl2: magnesium chloride; NaCl: sodium chloride; NAD: nicotinamide adenine dinucleotide; NADH: nicotinamide adenine dinucleotide hydride; $\mathrm{NADPH}$ : nicotinamide adenine dinucleotide phosphate; ncRNA: non-coding RNA; nc-sRNA: non-coding small RNA; PHB: polyhydroxybutyrate;

PR: proteorhodopsin; RNA: ribonucleic acid; rRNA: ribosomal RNA; Slayer: surface layer; snoRNA: small nucleolar RNAs; TCA: tricarboxylic acid; TPM: transcripts per million; tRNA: transfer RNA; UTR: untranslated but transcribed region

\section{Acknowledgements}

None.

\section{Author contributions}

$H B$, FRV and $A B M C$ conceived and designed the experiments. HB performed the experiments. HB, ABMC. LP and RR analyzed the data. All authors contributed to writing of the manuscript and approved the final manuscript.

\section{Funding}

The research leading to these results has received funding from the European Union Seventh Framework Program (FP7/2007-2013- MaCuMBA project) under grant agreement $n^{\circ} 311,975$ (HB and FRV; salary (in part), consumables and sequencing costs). Salaries of RR and ABMC were partly payed by the projects "VIREVO" CGL2016-76273-P [AEI/FEDER, UE], from Agencia Estatal de Investigación (AEI) y por la Unión Europea a través del Fondo Europeo de Desarrollo Regional FEDER - "Una manera de hacer Europa"; Acciones de dinamización "REDES DE EXCELENCIA" CONSOLIDER- CGL2015-71523-REDC from the Spanish Ministerio de
Economía, Industria y Competitividad and PROMETEO II/2014/012 "AQUAME1" from Conselleria d'Educació, Cultura i Esport. Direcció General d'Universitat, Estudis Superiors i Ciència. Generalitat Valenciana.

\section{Availability of data and materials}

The transcriptome sequencing data has been submitted to NCBI SRA and is available with the bioproject number PRJNA362183 and the SRA accession numbers SRR5714110 (light sample) and SRR5714111 (dark sample).

\section{Competing interest}

The submitted manuscript contains original research only which is not subject to any conflicts of interest, it has not been previously published and has not been submitted for publication elsewhere.

\section{Ethics approval and consent to participate}

The strain used in this study, Haloquadratum walsbyi strain HBSQ001, is from the personal culture collection, maintained since 2003 by Henk Bolhuis.

\section{Consent for publication}

Not applicable.

\section{Publisher's Note}

Springer Nature remains neutral with regard to jurisdictional claims in published maps and institutional affiliations.

\section{Author details}

'Department of Marine Microbiology and Biogeochemistry, Royal Netherlands Institute for Sea Research (NOIZ) and Utrecht University, Den Hoorn, the Netherlands. 'Evolutionary Genomics Group, Departamento de Producción Vegetal y Microbiología, Universidad Miguel Hernández, San Juan de Alicante, Alicante, Spain. ${ }^{3}$ Faculty of Medicine, University Sarajevo School of Science and Technology, Sarajevo, Bosnia and Herzegovina.

Received: 16 February 2017 Accepted: 21 June 2017

Published online: 03 July 2017

\section{References}

1. Antón J, Llobet-Brossa E, Rodriguez-Valera F, Amann R. Fluorescence in situ hybridization analysis of the prokaryotic community inhabiting crystallizer ponds. Environ Microbiol. 1999;1(6):517-23. doi:10.1046/j.1462-2920.1999.00065.x.

2. Benlloch S, Lopez-Lopez A, Casamayor EO, Øvreås L, Goddard V, Daae FL, et al. Prokaryotic genetic diversity throughout the salinity gradient of a coastal solar saltern. Environ Microbiol. 2002;4(6):349-60. doi:10.1046/j.1462-2920. 2002.00306.x.

3. Walsby AE. A square bacterium. Nature. 1980;283(5742):69-71. doi:10. 1038/283069a0.

4. Bolhuis $\mathrm{H}$, te Poele EM, Rodriguez-Valera F. Isolation and cultivation of Walsby's square archaeon. Environ Microbiol. 2004;6(12):1287-91. doi:10. 1111/j.1462-2920.2004.00692.x.

5. Bolhuis H, Palm P, Wende A, Falb M, Rampp M, Rodriguez-Valera F, et al. The genome of the square archaeon Haloquadratum walsbyi : life at the limits of water activity. BMC Genomics. 2006;7:169. doi:10.1186/1471-2164-7-169.

6. Burns DG, Camakaris HM, Janssen PH, Dyall-Smith ML. Cultivation of Walsby's square haloarchaeon. FEMS Microbiol Lett. 2004;238(2):469-73. doi: 10.1016/j.femsle.2004.08.016.

7. Dyall-Smith ML, Pfeiffer F, Klee K, Palm P, Gross K, Schuster SC, et al. Haloquadratum walsbyi: limited diversity in a global pond. PLoS One. 2011; 6(6):e20968. doi:10.1371/journal.pone.0020968.

8. Podell S, Ugalde JA, Narasingarao P, Banfield JF, Heidelberg KB, Allen EE. Assembly-driven community genomics of a hypersaline microbial ecosystem. PLoS One. 2013;8(4):e61692. doi:10.1371/journal.pone.0061692.

9. Andrews JH, Harris RF. R- and K-selection and microbial ecology. In: Marshall KC, editor. Advances in microbial ecology. Boston, MA: Springer US; 1986. p. 99-147.

10. Reznick D, Bryant MJ, Bashey F. R-and K-selection revisited: the role of population regulation in life-history evolution. Ecology. 2002;83(6):1509-20.

11. Oren A. The ecology of Dunaliella in high-salt environments. J Biol Res. 2014;21(1):23. doi:10.1186/s40709-014-0023-y.

12. Øvreås L, Daae FL, Torsvik V, Rodriguez-Valera F. Characterization of microbial diversity in hypersaline environments by melting profiles and reassociation kinetics in combination with terminal restriction 
fragment length polymorphism (T-RFLP). Microb Ecol. 2003;46(3):291301. doi:10.1007/s00248-003-3006-3.

13. Zenke R, von Gronau S, Bolhuis H, Gruska M, Pfeiffer F, Oesterhelt D. Fluorescence microscopy visualization of halomucin, a secreted $927 \mathrm{kDa}$ protein surrounding Haloquadratum walsbyi cells. Front Microbiol. 2015; 6(249):249. doi:10.3389/fmicb.2015.00249.

14. Kuo $\mathrm{CH}$, Moran NA, Ochman $\mathrm{H}$. The consequences of genetic drift for bacterial genome complexity. Genome Res. 2009:19(8):1450-4. doi:10.1101/gr.091785.109.

15. Lobasso S, Lopalco P, Angelini R, Pollice A, Laera G, Milano F, et al. Isolation of Squarebop I bacteriorhodopsin from biomass of coastal salterns. Protein Expr Purif. 2012;84(1):73-9. doi:10.1016/j.pep.2012.04.017.

16. Talaue CO, del Rosario RC, Pfeiffer F, Mendoza ER, Oesterhelt D. Model construction and analysis of respiration in Halobacterium salinarum. PLoS One. 2016;11(3):e0151839. doi:10.1371/journal.pone.0151839.

17. Stoeckenius W. Walsby square bacterium - fine-structure of an orthogonal procaryote. J Bacteriol. 1981;148(1):352-\&.

18. Burns DG, Janssen PH, Itoh T, Kamekura M, Li Z, Jensen G, et al. Haloquadratum walsbyi gen. Nov., sp. nov., the square haloarchaeon of Walsby, isolated from saltern crystallizers in Australia and Spain. Int I Syst Evol Microbiol. 2007;57(Pt 2):387-92. doi:10.1099/ijs.0.64690-0.

19. Bolhuis H. Walsby's square Archaeon. In: Gunde-Cimerman N, Oren A, Plemenitaš A, editors. Adaptation to life at high salt concentrations in Archaea, Bacteria, and Eukarya. Dordrecht: Springer Netherlands; 2005. p. 185-99.

20. Coker JA, DasSarma P, Kumar J, Muller JA, DasSarma S. Transcriptional profiling of the model Archaeon Halobacterium sp. NRC-1: responses to changes in salinity and temperature. Saline Systems. 2007;3:6. doi:10.1186/ 1746-1448-3-6.

21. Moran-Reyna A, Coker JA. The effects of extremes of pH on the growth and transcriptomic profiles of three haloarchaea. F1000Res. 2014;3:168. doi:10. 12688/f1000research.4789.2.

22. Heyer R, Dorr M, Jellen-Ritter A, Spath B, Babski J, Jaschinski K, et al. High throughput sequencing reveals a plethora of small RNAs including tRNA derived fragments in Haloferax volcanii. RNA Biol. 2012;9(7):1011-8. doi:10.4161/rna.20826.

23. Kurt-Kizildogan A, Abanoz B, Okay S. Global transcriptome analysis of Halolamina sp. to decipher the salt tolerance in extremely halophilic archaea. Gene. 2017;601:56-64. doi:10.1016/j.gene.2016.11.042.

24. Gonzalez-Torres P, Pryszcz LP, Santos F, Martinez-Garcia M, Gabaldon T, Antón J. Interactions between closely related bacterial strains are revealed by deep transcriptome sequencing. Appl Environ Microbiol. 2015;81(24): 8445-56. doi:10.1128/AEM.02690-15.

25. Wagner GP, Kin K, Lynch VJ. Measurement of mRNA abundance using RNAseq data: RPKM measure is inconsistent among samples. Theory Biosci. 2012;131(4):281-5. doi:10.1007/s12064-012-0162-3.

26. Martin-Cuadrado AB, Pasic L, Rodriguez-Valera F. Diversity of the cell-wall associated genomic island of the archaeon Haloquadratum walsbyi. BMC Genomics. 2015;16(1):603. doi:10.1186/s12864-015-1794-8.

27. Sharma AK, Walsh DA, Bapteste E, Rodriguez-Valera F, Ford Doolittle W, Papke RT. Evolution of rhodopsin ion pumps in haloarchaea. BMC Evol Biol. 2007;7:79. doi:10.1186/1471-2148-7-79.

28. Yokoyama $\mathrm{K}$, Imamura $\mathrm{H}$. Rotation, structure, and classification of prokaryotic $\mathrm{V}$ ATPase. J Bioenerg Biomembr. 2005;37(6):405-10. doi:10.1007/s10863-005-9480-1.

29. Rangachari K, Davis CT, Eccleston JF, Hirst EM, Saldanha JW, Strath M, et al. SufC hydrolyzes ATP and interacts with SufB from Thermotoga maritima. FEBS Lett. 2002;514(2-3):225-8. doi:10.1016/S0014-5793(02)02369-4.

30. Makarova KS, Wolf YI, Koonin EV. Archaeal clusters of Orthologous genes (arCOGs): an update and application for analysis of shared features between Thermococcales, Methanococcales, and Methanobacteriales. Life. 2015;5(1): 818-40. doi:10.3390/life5010818.

31. Egli M. Architecture and mechanism of the central gear in an ancient molecular timer. J R Soc Interface. 2017;14(128):20161065. doi:10.1098/rsif.2016.1065.

32. Whitehead K, Pan M, Masumura K, Bonneau R, Baliga NS. Diurnally entrained anticipatory behavior in archaea. PLoS One. 2009;4(5):e5485. doi:10.1371/ journal.pone.0005485.

33. Heyes CD, El-Sayed MA. Thermal properties of bacteriorhodopsin. J Phys Chem B. 2003;107(44):12045-53. doi:10.1021/jp035327b.

34. Tarasov V, Schwaiger R, Furtwangler K, Dyall-Smith M, Oesterhelt D. A small basic protein from the brz-brb operon is involved in regulation of bop transcription in Halobacterium salinarum. BMC Mol Biol. 2011;12(1): 42. doi:10.1186/1471-2199-12-42.

35. Riedel T, Tomasch J, Buchholz I, Jacobs J, Kollenberg M, Gerdts G, et al. Constitutive expression of the proteorhodopsin gene by a flavobacterium strain representative of the proteorhodopsin-producing microbial community in the North Sea. Appl Environ Microbiol. 2010;76(10):3187-97. doi:10.1128/AEM.02971-09.

36. Tarasov W, Besir H, Schwaiger R, Klee K, Furtwangler K, Pfeiffer F, et al. A small protein from the bop-brp intergenic region of Halobacterium salinarum contains a zinc finger motif and regulates bop and crtB1 transcription. Mol Microbiol. 2008; 67(4):772-80. doi:10.1111/j.1365-2958.2007.06081.x.

37. Elevi Bardavid R, Oren A. Dihydroxyacetone metabolism in Salinibacter ruber and in Haloquadratum walsbyi. Extremophiles. 2008;12(1):125-31. doi:10.1007/s00792-007-0114-x.

38. Brenneis M, Hering O, Lange C, Soppa J. Experimental characterization of cis-acting elements important for translation and transcription in halophilic archaea. PLoS Genet. 2007;3 doi:10.1371/journal.pgen.0030229.

39. Slager J, Veening JW. Hard-wired control of bacterial processes by chromosomal gene location. Trends Microbiol. 2016;24(10):788-800. doi:10.1016/j.tim.2016.06.003.

40. Ardell DH, Kirsebom LA. The genomic pattern of tDNA operon expression in E. coli. PLoS Comp Biol. 2005;1(1):e12. doi:10.1371/journal.pcbi.0010012.

41. Lundgren M, Andersson A, Chen L, Nilsson P, Bernander R. Three replication origins in Sulfolobus species: synchronous initiation of chromosome replication and asynchronous termination. Proc Natl Acad Sci U S A. 2004;101(18):7046-51. doi:10.1073/pnas.0400656101.

42. Wu Z, Liu H, Liu J, Liu X, Xiang H. Diversity and evolution of multiple orc/ cdc6-adjacent replication origins in haloarchaea. BMC Genomics. 2012;13: 478. doi:10.1186/1471-2164-13-478.

43. Legault BA, Lopez-Lopez A, Alba-Casado JC, Doolittle WF, Bolhuis $H_{\text {, }}$ Rodriguez-Valera F, et al. Environmental genomics of "Haloquadratum walsbyi" in a saltern crystallizer indicates a large pool of accessory genes in an otherwise coherent species. BMC Genomics. 2006;7:171. doi:10.1186/1471-2164-7-171.

44. Rodriguez-Valera F, Martin-Cuadrado A-B, Bolhuis H. Haloquadratum. John Wiley \& Sons, Ltd: Bergey's Manual of Systematics of Archaea and Bacteria; 2015.

45. Lieleg O, Lieleg C, Bloom J, Buck CB, Ribbeck K. Mucin biopolymers as broad-spectrum antiviral agents. Biomacromolecules. 2012;13(6):1724-32. doi:10.1021/bm3001292.

46. Offner S, Wanner G, Pfeifer F. Functional studies of the gvpACNO operon of Halobacterium salinarium reveal that the GvpC protein shapes gas vesicles. J Bacteriol. 1996;178(7):2071-8.

47. Offner $\mathrm{S}$, Hofacker A, Wanner G, Pfeifer F. Eight of fourteen gvp genes are sufficient for formation of gas vesicles in halophilic archaea. J Bacteriol. 2000:182(15):4328-36. doi:10.1128/jb.182.15.4328-4336.2000.

48. Muller JA, DasSarma S. Genomic analysis of anaerobic respiration in the archaeon Halobacterium sp. strain NRC-1: dimethyl sulfoxide and trimethylamine $\mathrm{N}$-oxide as terminal electron acceptors. J Bacteriol. 2005; 187(5):1659-67. doi:10.1128/JB.187.5.1659-1667.2005.

49. Hofacker A, Schmitz KM, Cichonczyk A, Sartorius-Neef S, Pfeifer F. GvpE- and GvpD-mediated transcription regulation of the $p$-gvp genes encoding gas vesicles in Halobacterium salinarum. Microbiology. 2004;150(Pt 6):1829-38. doi:10.1099/mic.0.27078-0.

50. Scheuch S, Pfeifer F. GvpD-induced breakdown of the transcriptional activator GvpE of halophilic archaea requires a functional p-loop and an arginine-rich region of GvpD. Microbiology. 2007;153(Pt 4):947-58. doi:10.1099/mic.0.2006/004499-0.

51. Cannio R, Fiorentino G, Morana A, Rossi M, Bartolucci S. Oxygen: friend or foe? Archaeal superoxide dismutases in the protection of intra- and extracellular oxidative stress. Front Biosci. 2000;5:D768-79.

52. May BP, Dennis PP. Evolution and regulation of the gene encoding superoxide dismutase from the archaebacterium Halobacterium cutirubrum. J Biol Chem. 1989;264(21):12253-8.

53. Dawes $E A$, Senior PJ. The role and regulation of energy reserve polymers in micro-organisms. Adv Microb Physiol. 1973;10:135-266.

54. Lillo JG, Rodriguez-Valera F. Effects of culture conditions on poly(betahydroxybutyric acid) production by Haloferax mediterranei. Appl Environ Microbiol. 1990;56(8):2517-21.

55. Wurtzel O, Sapra R, Chen F, Zhu Y, Simmons BA, Sorek R. A single-base resolution map of an archaeal transcriptome. Genome Res. 2010;20(1):13341. doi:10.1101/gr.100396.109.

56. Langmead B, Salzberg SL. Fast gapped-read alignment with bowtie 2. Nat Methods. 2012;9(4):357-9. doi:10.1038/nmeth.1923.

57. Li H, Handsaker B, Wysoker A, Fennell T, Ruan J, Homer N, et al. The sequence alignment/map format and SAMtools. Bioinformatics. 2009;25(16): 2078-9. doi:10.1093/bioinformatics/btp352. 
58. Carver T, Harris SR, Otto TD, Berriman M, Parkhill J, McQuillan JA. BamView: visualizing and interpretation of next-generation sequencing read alignments. Brief Bioinform. 2013;14(2):203-12. doi:10.1093/bib/bbr073.

59. Rutherford K, Parkhill J, Crook J, Horsnell T, Rice P, Rajandream MA, et al. Artemis: sequence visualization and annotation. Bioinformatics. 2000;16(10): 944-5. doi:10.1093/bioinformatics/16.10.944.

60. Bateman A, Coin L, Durbin R, Finn RD, Hollich V, Griffiths-Jones S, et al. The Pfam protein families database. Nucleic Acids Res. 2004;32(Database issue): D138-41. doi:10.1093/nar/gkh121.

Submit your next manuscript to BioMed Central and we will help you at every step:

- We accept pre-submission inquiries

- Our selector tool helps you to find the most relevant journal

- We provide round the clock customer support

- Convenient online submission

- Thorough peer review

- Inclusion in PubMed and all major indexing services

- Maximum visibility for your research

Submit your manuscript at www.biomedcentral.com/submit 